\title{
Zazen: práctica desde la vacuidad ${ }^{1}$ Zazen: A Practice from Emptiness
}

\author{
Lina Marcela Cadavid Ramírez \\ Universidad Católica Luis Amigó | Colombia \\ Contacto: lina.cadavidra@amigo.edu.co
}

\section{Resumen}

Este artículo desarrolla una reflexión sobre la ética como modo de vida a partir de la práctica del zazen, para ello se nutre de anécdotas y narraciones de los maestros de la tradición Zen cuyas palabras se hacen significativas en el horizonte de la vacuidad (śünyatā), dimensión que posibilita hablar de una ética desde las singularidades de esta tradición. El texto se divide en tres partes, la primera, la introducción que presenta el marco de nuestro planteamiento; la segunda, la discusión, que dialoga con esta tradición a través de las palabras de los maestros; y por último la conclusión que reafirma la necesidad de comprender la relación entre zazen y śünyatā.

Palabras clave: vacuidad, zazen, Zen, práctica, forma de vida, ethos

\begin{abstract}
This article develops a reflection on ethics as a way of life from the practice of zazen, drawing from anecdotes and stories from masters of the Zen tradition whose words become significant on the horizon of emptiness (śünyatā). This dimension makes it possible to speak of an ethic from the singularities of this tradition. The text is divided into three parts, the first, the introduction that presents the framework of our approach; the sencond, the discussion, which dialogues with this tradition through the words of the teachers; and finally the conclusion that reaffirms the need to understand the relationship between zazen and śünyatā.
\end{abstract}

Keywords: emptiness, zazen, Zen, practice, way of life, ethos

${ }^{1}$ Este texto es una versión ampliada de la ponencia que con el mismo nombre se presentó en el Seminario Internacional de Filosofía Japonesa: hacia el si mismo ecológico-comunitario, organizado por el Colegio de Filosofía, UNAM, en el mes de noviembre de 2019 en Ciudad de México, cuya participación fue apoyada por la Institución en la que soy docente, la Universidad Católica Luis Amigó (Colombia), y la Fundación Japón (México). 


\section{Introducción}

Las diversas crisis que enfrentan hoy a la cultura occidental consigo misma y que repercuten en el orden planetario, nos convocan a reflexionar desde una perspectiva intercultural, como lo han hecho figuras de la filosofía contemporánea continental como Raimon Panikkar (1996; 1997; 2002; 2005), Juan Arnau (2005; 2007), François Jullien (2007; 2008; 2009a), entre muchos otros. Menciono estos tres autores en particular por su interés en entablar un diálogo con las tradiciones índica, budista y taoísta en un movimiento de ida y vuelta para abrir el horizonte de conceptos, palabras y visiones de mundo que se han anquilosado, además en sus obras es claro un interés por leer los textos clásicos de dichas tradiciones y hacer resonar en Occidente la vitalidad que adquiere la praxis. Sus propuestas bien pueden enmarcarse en un proyecto más amplio, que en la actualidad apunta a un pensamiento sobre el sí mismo ecológico, expresión que ya alude a un cuestionamiento del paradigma moderno de la subjetividad, toda vez que se reconoce una dimensión humana más allá del cogito y su solipsismo — superable sólo desde la trascendencia (Descartes, 1997) — . En contraste, la palabra "ecológico" habla de un yo anclado al mundo natural, social, de la vida y consciente, arraigo que reclama una renovación en el ethos de los hombres y mujeres de este siglo.

Ya en el libro la Trama de la vida, Fritjof Capra cita a Arne Naes para explicar lo propio de la ética de un paradigma ecológico profundo, ${ }^{2}$ según éste:

El cuidado (care) fluye naturalmente cuando el "sí mismo" se amplía y profundiza hasta el punto de sentir y concebir la protección de la Naturaleza libre como la de nosotros mismos [...] Al igual que no precisamos de la moral para respirar [...] [igualmente] si nuestro "sí mismo", en el sentido más amplio, abarca a otro ser, no precisamos de ninguna exhortación moral para evidenciar cuidado [...] Cuidamos por nosotros mismos, sin precisar ninguna presión moral [...] Si la realidad es como la que experimenta nuestro ser ecológico, nuestro comportamiento sigue natural y perfectamente normas de estricta ética medioambiental. (Citado en Capra, 1998: 33)

Ahora bien, la cita anterior permite introducir la cuestión que me propongo trabajar en este artículo a partir de la formulación de dos cuestiones: una, cómo

${ }^{2}$ Capra distingue entre una antropología superficial, que continúa siendo antropocéntrica y en esta medida mantiene la idea de una superioridad de los valores humanos conservando para la naturaleza una perspectiva instrumental, y una antropología profunda, la cual reconoce el valor propio de todo ser humano y entiende el mundo como "una red de fenómenos interconectados e interdependientes" (1998: 29). 
puede un individuo conquistar ese fluir natural, esa expansión del sí mismo que no encuentra ya al ego como barrera; otra, cómo es posible una moral sin exhortación o presión de normas o imperativos. Llevaré a cabo mi empresa intentando un atisbo de respuesta a estas preguntas desde el zazen entendido como una práctica desde la vacuidad (śūnyatā), recurriendo a algunas enseñanzas y anécdotas de maestros zen para clarificar mi punto de vista sobre cómo se puede, desde esta práctica, salir de ese solipsismo moderno que sigue vigente.

\section{Discusión}

Empezaré diciendo que esta dimensión ética del Zen es una cuestión que no es fácil nombrar y que soy consciente de que puede haber muchos malentendidos cuando se piensa el Zen desde una dimensión ética, teniendo en cuenta que la pregunta se hace desde Occidente y su sentido de este término. Por esta razón, me permito usar la palabra ethos en su sentido de "residencia, morada, lugar donde se habita" (Ramón, 2006: 109) para hablar más bien de un modo de vida que de una reflexión ética material o formal. Una anécdota sobre el maestro Hakuin bien puede clarificar lo que intento señalar:

The Zen master Hakuin was praised by his neighbors as one living a pure life. A beautiful Japanese girl whose parents owned a food store lived near him. Suddenly, without any warning, her parents discovered she was with child. This made her parents angry. She would not confess who the man was, but after much harassment at last she named Hakuin. In great anger the parents went to the master. "Is that so?" was all he would say. After the child was born it was brought to Hakuin. By this time he had lost his reputation, which did not trouble him, but he took very good care of the child. He obtained milk from his neighbors and everything else the little one needed. A year later the girl-mother could stand it longer. She told her parents the truth - that the real father of the child was a young man who worked in the fish market. The mother and the father of the girl at once went to Hakuin to ask his forgiveness, to apologize at length, and to get the child back again. Hakuin was willing. In yielding the child, all he said was: "Is that so?" (Citado en Naranjo y Ornstein 1971: 24)

Cuando se lee esta anécdota uno se pregunta: ¡es Hakuin nada más que un buen hombre del pueblo que acepta los vejámenes de sus vecinos? Si es de este modo, ¿a la espera de qué, o por qué no tiene nada que esperar? ¿Indica su respuesta, “ ¿es asi??, 
su capacidad para controlar sus pasiones? ¿La espera paciente porque el bien surja para el que sufre injustamente? ¿La conquista de una libertad que es dueńa furiosa de su futuro o dueña racional de su presente? ¿El desapego a toda ilusión de felicidad en orden al deber que ha de cumplirse? ¿Su buena voluntad como hecho irrebatible de la vida moral? ¿La constitución paulatina de una manera inédita de relación consigo mismo y los otros? ¿Su capacidad para escoger entre máximas tras un razonamiento práctico adecuado? $\mathrm{O}$, ¿es sólo una simulación burguesa de la virtud?

Como la anécdota de Hakuin, hay muchas narraciones y sentencias zen que parecen advertirnos el mérito de la serenidad y la calma, su superioridad sobre la impermanencia de los fenómenos para lograr el ajuste intelectual, afectivo, psíquico, corporal y espiritual a la Naturaleza de las Cosas. Como afirma el maestro zen Daishi (2000), "si despiertas y comprendes ya no necesitas hacer esfuerzos vanos: nada pertenece al orden de $u i$ " (84), es decir, nada atañe a la enseñanza limitada que nos dispone contra la vida cósmica, como interpreta el maestro zen japonés Deshimaru las palabras del maestro chino del siglo viII. Daishi, además, parece describir a la perfección la vida que aspira el maestro, monje y practicante zen: "retirarse a las profundas montańas, vivir en una pequeña ermita, sentado bajo un gran pino, sereno y tranquilo [...] vida sencilla y serena, verdadera belleza" (Daishi, 2000: 84). ¿Qué podría suponer una lectura desde Occidente de estas palabras de los maestros zen? ¿Cómo describir a Hakuin? ¿Acaso como un hombre "pacífico, justo, moderado, respetuoso, considerado, valiente, casto, honrado, fiel, creyente, recto, confiado, abnegado, compasivo, altruista, escrupuloso, simple, benévolo, justo, generoso, indulgente, obediente, desinteresado, no envidioso, bondadoso, trabajador" (Nietzsche, 2006: 91)? Es decir, ¿apunta el zazen a la conquista de estos valores tras su práctica continúa? $\mathrm{O}$ de otra forma ¿`cómo hace la práctica de zazen a un individuo recto?

Me parece necesario aclarar el carácter problemático del lenguaje en estas preguntas. Su formulación, de alguna manera, ya nos pierde en el camino de una posible comprensión, pues ¿̨hay algo que deba ser alcanzado o siquiera conquistado? En contraste con esta idea, es decir, la de empeñarnos en modelarnos moralmente, puede traerse a la memoria una de las enseñanzas del primer patriarca Zen, Bodhidharma, consignada en su Tratado sobre el linaje de la fe: "un buda no observa los preceptos. Un buda no hace ni bien ni mal. Un buda no es activo ni perezoso. Un buda es alguien que hace nada, alguien que ni siquiera puede enfocar su mente en un buda. Un buda no es un buda" (1994: 35). No obstante, ¿estas palabras dan una respuesta a nuestras preguntas? $\mathrm{O}$, ¿acaso alivian nuestro anhelo por entender cómo se fluye naturalmente sin precisar apremio moral alguno, tal como lo señala Naes en su cita? 
Ahora bien, tal vez sea imperioso no pasar por alto la alusión a la fe del título de la obra de Bodhidharma, pues tal como lo explican los maestros Yasutani-roshi y Kapleau-roshi — quienes remontan este componente de fe hasta Dōgen-: "la base del shikan-taza ${ }^{3}$ es la fe inamovible de que al sentarse como lo hizo buda, con la mente vacía de toda concepción, toda creencia o punto de vista, se actualiza o descubre la Mente-bodhi ${ }^{4}$ inherentemente iluminada con la cual todo ser está dotado" (2005: 7). Lo interesante es, tal como me lo explicó Gally-roshi en un dokusan —encuentro entre maestro y alumno_- que esta fe es en uno mismo, no en Buda como individuo diferente a mí o como iluminado superior a mí, pues como lo expresa el mismo Bodhidharma sólo ve a Buda quien ya es Buda, es decir, no quien ha llegado a ser Buda sino quien reconoce que siempre ha sido un Buda. Dice pues Bodhidharma (1994):

La única razón para la que vine a China fue para trasmitir la enseñanza instantánea del Mahayana: Esta mente es el buda. No hablo de preceptos, devociones o prácticas ascéticas como sumergirse en agua y fuego, pisar cuchillos, comer una comida al día o no descansar nunca. Esas son enseñanzas fanáticas y provisionales. Una vez que reconoces tu asombrosa y milagrosa naturaleza consciente, tuya será la mente de todos los budas". (59-61)

${ }^{3}$ Será el patriarca japonés Dōgen quien introducirá una forma de zazen más ardua, el shikan-taza —que literalmente significa nada más que sentarse_y que exige de quien medita "que [su] mente esté inmersa con absoluta intensidad en solo sentarse" (Kapleau, 2005: 60) sin aferrase siquiera a contar las respiraciones — permaneciendo sentado mirando la pared, en postura de loto, con la espalda recta (como es normal en zazen) — y esforzándose por evitar que la mente se disperse.

${ }^{4}$ En el Dhammaphada, texto de la escuela Theravāda que recoge, a manera de sentencias en 26 capítulos, las enseñanzas de Buda, originalmente en lengua pali, la noción de mente no se define como una categoría. En la traducción sanscrita del Dhammapada se usa la palabra chitta para mente, de la raíz chit, que se traduce como pensar. Es decir, la mente no se concibe en el budismo como una sustancia, digamos a la manera cartesiana, sino que es una palabra para referirse al flujo de los pensamientos. Para el budismo, la agitación que es común a este flujo es producto de las pasiones, especialmente el odio. En el budismo zen, además, por ejemplo en las enseńanzas de Bodhidharma, se habla de la mente para referirse a aquella experiencia que se alcanza con la práctica del zazen, gracias a la cual los pensamiento dejan de emerger de forma constante e inestable, esa mente podría ser calificada como śūnya: "Tú preguntas; esa es tu mente. Yo respondo: esta es mi mente. Si no tuviese mente, ¿cómo podría responder? Si no tuviese mente ¿cómo podrías preguntar?” (Bodhidharma, 1994: 27). En esta cita puede leerse cómo Bodhidharma usa la palabra mente en dos sentidos, fragmento que puede comprenderse a la luz de la caracterización que se da en el Dhammapada. Finalmente, en el budismo zen también se usa la palabra Mente (con mayúscula) para referirse a la conciencia total, es decir, a "sólo escuchar, sólo ver al mirar, etcétera” (Kapleau, 2005: 409). 
Según lo anterior, parece imprescindible en la realización de ese acto desprovisto de esfuerzo (anabhoga-carya) el zazen y la fe —en el sentido ya aludido-. Ahora bien, esto quiere decir que una actitud ética como la descrita por Naes difícilmente podría alcanzarse solo por los medios del razonamiento discursivo, el cual es importante y necesario pues como racionalidad comunicativa, en el sentido habermasiano del término, pone en evidencia las diferentes formas de dominio que se ciernen sobre el mundo de la vida y abre lugar a una crítica fundamental que amplía la racionalidad occidental. Pero, al mismo tiempo, si algo debe aportar la reflexión sobre el zazen para Occidente es la dimensión constitutiva de su práctica, gracias a la cual se revelan los diversos automatismos de nuestro pensamiento y comportamiento. Al practicar zazen se muestra al individuo aquella condición que describe tanto al asceta como al monje, pero en últimas a todo aquel que se entrega a la postura sin motivación ni espera ajena a la misma postura, sin signos de teleología imperante, pues ese que practica con fe e intensidad tiene:

$\mathrm{Al}$ andar una perfecta comprensión del andar; al detenerse, una perfecta comprensión de la detención; y al sentarse, entiende perfectamente su acción de sentarse..., y cualquier cosa que haga, él entiende perfectamente lo que hace... Al ir hacia delante o al volver, él tiene una exacta comprensión de lo que hace; mirando... él tiene una exacta comprensión de lo que hace; levantando el brazo o dejándolo caer, él tiene una exacta comprensión de lo que hace; llevando una ropa... tiene una exacta comprensión de lo que hace; comiendo, bebiendo, masticando y saboreando, tiene una exacta comprensión de lo que hace. (Eliade, 2005: 76)

Es inevitable: nuestros automatismos nos acompañan y configuran más allá de nuestra vigilia, de nuestra atención diaria o de la observación sobre nosotros mismos para hacer parte de la trama que nos sostiene como seres que decimos "yo". Pero siendo así, ¿cómo, entonces, llegar a actuar como lo hace Hakuin? Recurro a Daishi (2000), de nuevo, para intentar una respuesta:

incluso durante zazen, nuestra mente siempre está llena de todo tipo de pensamientos, de fenómenos, de ilusiones que surgen del ego [...] Durante zazen estas burbujas se forman sin cesar en nuestro espíritu: cólera, deseo, ignorancia o ansiedad [...] Sobretodo ansiedad [pero] Durante zazen abandonamos el ego y también nuestras diferencias entre el bien y el mal. $(18,21-22)$

Sin embargo, la pregunta parece persistir ¿cómo se logra esto? Daishi (2000) respondería (y posiblemente muchos otros maestros zen) de manera un tanto para- 
dójica: a través de un esfuerzo que no es (sólo y tal vez no sea) esfuerzo de la voluntad, sino que ha de trasnombrarse como una "total apertura al devenir" (26), tras ese entrenamiento de estirar la columna vertebral, recoger la barbilla, inclinar apenas un poco la mirada, respirar abdominalmente, descansar sobre el abdomen, mantener las piernas cruzadas, la lengua en el paladar, aquietando el cuerpo para interrumpir el movimiento propio de la mente hasta ver el carácter vacuo de todo, tal y como se logra en la postura de zazen en medio de la cotidianidad sin revés ni trascendencia.

Otra anécdota zen, esta vez sobre el sexto patriarca Huineng, puede permitirme seguir esclareciendo la cuestión que intento presentar. El maestro de Huineng, Hongren, decidió

que había llegado el momento de elegir a su sucesor [...] Hongren pidió a todos sus discípulos que escribiesen un poema en el que expresaran su comprensión. El autor del mejor poema sería elegido como el sexto patriarca. Todos los monjes dieron por descontado que el discípulo principal de Hongren, un monje llamado Shenxiu, sucedería al maestro [...] El poema de Shenxiu fue: "El cuerpo es el árbol del Bodhi; la mente, el pedestal de un espejo brillante. Siempre debemos intentar pulirlo para que no se acumule el polvo". Huineng escuchó a uno de los monjes recitar el poema y compuso el suyo [... Su poema respondía al de Shenxiu y decía: "Originalmente el Bodhi no tiene ningún árbol. El espejo tampoco tiene ningún pedestal. La naturaleza búddhica desde siempre es clara y pura, luego, ¿dónde podría haber polvo?” (Citado en López, 2009: 359-360)

Ahora bien, el poema de Shenxiu apunta a una relación con nosotros como anhelo por perfeccionarnos moralmente a través de prácticas o del reconocimiento de un código interno o externo que actúa sobre el cuerpo, la mente o la conducta, para procurarnos un estado de excelencia, felicidad, pureza o deber cumplido: en todo caso se trata de mantener limpio aquello que se ve obscurecido por múltiples factores que evitan o impiden cierta relación moral con nosotros mismos. En contraste, el poema de Huineng parece cortar toda teleología en el ámbito ético, apuntando al reconocimiento de algo que siempre podemos llevar a cabo pero que olvidamos cómo, pues al sentarse en zazen no se perfecciona un yo, sea este esencial o no.

Así, frente a una moral que se afinca en la exploración de la interioridad con el propósito de pulirla para que no se acumule el polvo, que supone la necesidad de un acontecimiento interior que pueda o no concretarse en una acción y que sitúa al sujeto como promotor de una autonomía de la conciencia (Jullien, 2009b), estaría la práctica desde la vacuidad que está lejos de referirse a una renuncia, apatía o 
desapego. En el zen, śünyatā (vacuidad) se refiere a que "la realidad no está formada por entidades separadas y fijas, toda forma de existencia es relativa, porque depende del resto para existir, todo está en todo en un proceso abierto de interrelaciones" (Bouso, 2012: 99). Así, la realidad se compone de lo relativo que cambia de múltiples formas y de existencias finitas que dependen entre sí, lo que orienta la mirada hacia aquello que revela la forma del ser: como todo es impermanente e insustancial, la realidad no necesita ser sustentada desde la trascendencia o la quididad, basta con reconocer que la realidad es vacuidad.

Incluso, mantener los ojos abiertos frente a la pared mientras se está en zazen es signo de que la práctica no tiene por principio alejarse del mundo fenoménico. Luego, practicar en la vacuidad se despliega en varias dimensiones: en el ámbito social se refiere a evitar un exorbitante compromiso con la sociedad organizada; en la dimensión de la praxis, alude a la meditación que permite orientarnos desde un antes de los valores; en el ámbito de la salud personal, adviene a la manera de prácticas que invierten las formas automatizadas de relación con nuestra propia fisiología; en el ámbito espiritual se propicia un ayuno de sacrificios y ritos. Así pues, en el ser despierto en zazen se invierte radicalmente las formas convencionales y automáticas que se adoptan al seguir la inercia que imprime la vida en sociedad sin tener por ello que alejarse del mundo de la vida; despertar, pues, no tiene que ver con un progreso que termina en una meta épica o última, pero sí con una vuelta sin movimiento hacia lo posible que nada fija y que no reduce la nada a esencia, totalidad o absoluto. De este modo, la práctica de zazen está lejos de devenir en prescripción directa sobre la conducta ética, pero sí llevar al límite al practicante para que se ejercite en las variadas formas de experiencia de la vacuidad: la vacuidad del Buda, la vacuidad de su doctrina, la vacuidad de la enseñanza, la vacuidad de los preceptos, la vacuidad del yo, así como la relativización de la importancia del pensamiento conceptual como una vía de comprensión.

Ahora bien, la práctica de zazen no es la única que nos hace hábiles para fluir naturalmente. En el ámbito de la filosofía, las tesis de Pierre Hadot (2006; 2009) y Michel Foucault $(2000 ; 2001 ; 2008)$ lograron establecer consideraciones conceptuales inéditas al hacer de las escuelas filosóficas griegas el núcleo de sus análisis éticos, tradiciones ya lejanas en el tiempo, separadas de nuestra mentalidad por la religión cristiana, que podían, no obstante, leerse a la luz de las prácticas como ejercicios para disponerse al acceso a la verdad que en vez de guiarse por un código moral externo se concibieron como un "trabajo de constitución de sí mismo, esto es, de la formación de una relación consigo mismo que fuera plena, acabada, completa, autosuficiente y capaz de producir esta transfiguración del sujeto que es la dicha de estar consigo mismo" (Castro, 2004: 47), o como formas de entrenamien- 
to continúo que permiten una conversión de la mirada, que abren la posibilidad al individuo de volver a "situarse en la perspectiva del todo" (Hadot, 2006: 24).

Ahora bien, esto para mí señala el aspecto, a todas luces relevante, de las prácticas en la renovación de un discurso filosófico sobre la ética y que permite introducir cuestiones como esa dimensión del goce de sí mismo que comporta el ser integrado en una perspectiva cósmica que no debería ser obviada, pues el "proceso de interiorización está inseparablemente unido a otro proceso gracias al cual uno se eleva a un nivel psíquico superior en el que encuentra otro tipo de exteriorización, otro tipo de relación con el exterior, una nueva manera de ser-en-elmundo" (Hadot, 2006: 272). La introducción de las prácticas en la reflexión ética permite pensar sobre cómo el individuo constituye un modo de vida ético en vez de centrar la reflexión sobre el carácter obligatorio de la acción moral, que, en últimas, busca "procedimientos para establecer normas morales válidas para todos" (Ramón, 2006: 109). Pero la radicalidad del zazen nos deja estupefactos en cuanto a la naturaleza de su práctica, pues la manera en que [el zazen] disminuye esa importancia de las normas válidas para todos se trasluce al advertirnos de nuestro afán de conseguir algo, en ese sentido, el zazen no se deja manipular como medio para conseguir algo y corta constantemente nuestro anhelo por sumergir la práctica en la teleología, como Bodhidharma (1994) señala: "Un buda está libre de causa y efecto. Decir que alcanza algo es calumniarlo ¿Qué es lo que consigue? Concentrarse en una mente, un poder, una compresión o una visión, resulta imposible para un buda [...] La naturaleza de su mente está prácticamente vacía. Está libre de práctica y realización" (35).

De esta forma, lo que acaece, pues, en el que practica, podría decirse que es el vacío o el fluir (Han, 2015), y en ese fluir las cosas brillan: no en su carácter substancial sino en su estar presentes, pues el vacío avivaría la llama de las cosas cuya presencia no es ya la mera apariencia de una ausencia. Así, gracias al zazen se abandona el ámbito de la sustancia que clausura la experiencia bajo el dominio de la discriminación y la oposición, para procurar dejarlas ser en el ejercitarse continuo de no imponerse sobre ellas. De este modo, al no discriminar ni oponer, las cosas fluyen, pasando las unas a las otras (Han, 2015), experiencia que resulta asombrosa desde el ámbito de la sustancia en el que una cosa no puede transformarse en otra, pero que desde la vacuidad bien podría describirse como "una visión cotidiana del vacío" (2015: 64), que remite a la experiencia de la disolución de la "rigidez substancial" (2015: 67) que se suele imponer a las cosas. De este modo para quien es zazen, su ejercitación "hace, por así decirlo, que el corazón ayune, hasta que se le haga accesible otro ser, un ser que 'es' sin apetencia” (2015: 85). 
Quisiera terminar este apartado con una anécdota más, pero esta vez tomada de la sabiduría de los padres del desierto, y que es citada por Thomas Merton (2008) en su libro El zen y los pájaros del deseo:

Había una vez un gran eremita en las montañas, que fue atacado por unos salteadores. Sus gritos atrajeron a otros ermitańos de la vecindad, que se unieron para capturar a los criminales. Estos fueron trasladados, bajo custodia, a la gran ciudad, donde un juez los condenó a prisión. Pero entristeció y avergonzó a los hermanos, pues por su denuncia se había juzgado a los ladrones. Fueron al Abad y le narraron todo lo acontecido. Y el mayor escribió al eremita, diciendo: "Recuerda quien cometió la primera traición, y sabrás la razón de la segunda. A menos que te hubieran traicionado antes tus pensamientos, jamás hubieras enviado a estos hombres a que los juzgaran”. El ermitaño, conmovido por estas palabras, se puso de pie en el acto y fue a la ciudad y rompió los cerrojos de la celda liberando a los salteadores de la prisión y el tormento. (136)

La anécdota bien explica una afirmación que parece enunciar Merton en su obra y que resume lo que he tratado de presentar: para ser perfecto hay que dejar de ser moral. No obstante, podría agregarse, cuando olvidamos que somos perfectos, o mejor, no nos ejercitamos en la ejecución de nuestra perfección, se hace necesario tener en cuenta las máximas morales. El ermitaño, quien olvidó su voto fundamental de la pobreza, entendió las palabras del Abad como un llamado a violar las normas jurídicas guiado por una moral que tuvo como móvil la culpa de haberse olvidado a sí mismo, y allí se equivoca traicionado desde el principio por su olvido. De esta manera, puede concebirse que el zazen actualiza constantemente lo que somos y evita que incurramos en esa primera traición que desencadenará, inevitablemente, el accionar tanto de normas morales como jurídicas, de las cuales no será posible prescindir (y dudo que el Zen exhorte a ello) mientras sigamos llenos de nosotros mismos. En cuanto a ese esfuerzo que hacemos por fluir, y volviendo a la cita de Naes con la que iniciaba este artículo, lejos de distinguir entre la naturaleza y la técnica, como crecimiento natural por un lado y el hacer creador propio del hombre por otro, habría que considerar el origen único de todo en la transformación constante, pues todo en la naturaleza madura, sin intervención y fatiga. Por esta vía, el hombre profundiza su flujo y dinamismo interno, que tanto en el vasto espacio vacío del mundo como en sí mismo no deja de dar a la vida su esplendor. 


\section{Conclusión}

Hablar de una ética desde el Zen y su práctica, zazen, teniendo como horizonte śúnyatā revela que la vacuidad ni reemplaza la sustancia ética, ni contribuye al proceso de constitución de subjetividad, tampoco es ocasión para su destitución, ni supone posibilidad de transformación hacia un nuevo tipo de sujeción o forma diferente de subjetividad, y aludo a estas cuestiones porque, como mencioné en la discusión, la postura foucaultiana logró poner las prácticas en el centro de una reflexión ética como formación de sí gracias a su examen de la ética griega de los periodos clásico y helenístico, como un ejemplo histórico de un tipo de ética que, basada en el ascesis, permite la constitución de una relación moral consigo mismo y los otros. Ahora bien, este acercamiento filosófico se hizo desde una cultura que desconoció el problema del yo en la esfera moral, tal como lo trazara el cristianismo y extendiera posteriormente la modernidad: el yo como ámbito de interioridad no hace parte de la visión del mundo griego, pues, como indica Jean Pierre Vernant (1990), el yo "no está delimitado ni unificado: es un campo abierto de fuerzas múltiples [...] No hay introspección. El sujeto no constituye un mundo interior cerrado en el cual deba penetrar para reencontrarse o más bien descubrirse" (39-40). Entre tanto, las escuelas budistas sí desplegaron una reflexión en abierta oposición a las categorías fundamentales de la espiritualidad de los cuatro Samithā, especialmente las doctrinas del àtman y del fundamento absoluto de lo real, cuestiones que hicieron inocuas las ideas de la doctrina vedántica según la cual escapar a la rueda del karma requería la identificación ātman-brahman que preconizaban las Upanisad. En este contexto se erige la importancia de la práctica y la vacuidad en la conformación de un modo de vida. La leyenda china sobre el primer patriarca Zen, Bodhidharma, ejemplifica la anterior afirmación. Se cuenta que hallándose este sentado frente a la pared, el segundo patriarca "de pie junto a la nieve se cortó el brazo y se lo presentó, llorando: ‘iMi espíritu aún no ha encontrado la tranquilidad! Os lo ruego, tranquilizadme el espíritu'. 'Tráeme tu espíritu y yo te lo apaciguaré', respondió Bodhidharma. 'Lo he buscado y no puedo encontrarlo', dijo el segundo patriarca. 'Ahora ya has encontrado la tranquilidad', dijo Bodhidharma' (citado en Dunn Mascetti, 2007: 86). Este relato sobre Bodhidharma señala de manera explícita las particularidades que identifican al Zen desde sus comienzos: la práctica de la meditación frente a la pared sin un fundamento más allá o más acá, y el reconocimiento de que no hay nada que perseguir para alcanzar la liberación. Encuentro claro que las palabras de los patriarcas hacen más patente la descripción de zazen como práctica de la vacuidad toda vez que emerge desde su propia experiencia en la que śūnyatā evita su desactivación en ese fluir ecológico sin presión moral. 


\section{Referencias bibliográficas}

Arnau, Juan. (2005). La palabra frente al vacio. Filosofía de Nāgārjuna. México: Fondo de Cultura Económica.

Arnau, Juan. (2007). "Lenguaje y silencio en las tradiciones budistas". 'Ilu. Revista de Ciencias de las Religiones, (Anejo XIX), 85-105. https://revistas.ucm.es/ index.php/ILUR/article/view/ILUR0707330085A

Bodhidharma. (1994). Enseñanzas zen. Barcelona: Kairós.

Bouso, Raquel. (2012). Zen. Barcelona: Fragmenta.

Capra, Fritjof. (1998). La trama de la vida. Barcelona: Anagrama.

Castro, Edgardo. (2004). El vocabulario de Michel Foucault. Un recorrido por sus temas, conceptos y autores. Buenos Aires: Prometeo.

DAIshi, Yoka. (2000). El canto del inmediato satori (Taisen Deshimaru, Trad.). Barcelona: Kairós.

DHAMMAPADA. (2004). (Claudio Dossetti, trad.). Buenos Aires: Hastinapura.

Descartes, René. (1997). Meditaciones metafísicas. Madrid: Gredos.

Dunn Mascetti, Manuela. (2007). Zen. España: Evergreen.

Eliade, Mircea. (2005). La isla de Eutanasius. Madrid: Trotta.

Foucault, Michel. (2000). Hermenéutica del sujeto. México: Fondo de Cultura Económica.

Foucault, Michel. (2001). "Sobre la genealogía de la ética: una visión de conjunto de un trabajo en proceso". En Hubert Dreyfus y Paul Rabinow, Michel Foucault: más allá del estructuralismo y la hermenéutica. Argentina: Nueva visión. Foucault, Michel. (2008). Tecnologías del yo y otros textos afines. Barcelona: Paidós. НаDот, Pierre. (2006). Ejercicios espirituales y filosofía antigua. Madrid: Siruela. Hadot, Pierre. (2009). La filosofía como forma de vida. Barcelona: Alpha Decay. Han, Byung-Chul. (2015). Filosofía del budismo zen. Madrid: Herder.

Jullien, François. (2007). Nutrir la vida. Más allá de la felicidad. Buenos Aires: Katz. Jullien, François. (2008). La urdimbre y la trama. Buenos Aires: Katz.

Jullien, François. (2009a). Conferencia sobre la eficacia. Buenos Aires: Katz.

Jullien, François. (2009b). La sombra en el cuadro. Del mal o de lo negativo. Madrid: Arena.

Kapleau, Philip. (2005). Los tres pilares del zen. Enseñanza, práctica, iluminación. Ciudad de México: Pax.

Merton, Thomas. (2008). El zen y los pájaros del deseo. Barcelona: Kairós.

López, Donald S., Jr. (2009). El buddhismo. Introducción a su historia y sus enseñanzas. Barcelona: Kairós. 
Naranjo, Claudio; Ornstein, Robert E. (1971). On the psychology of meditation. Nueva York: Viking Press.

Nietzsche, Friedrich. (2006). El nihilismo europeo. Fragmentos póstumos (Otoño 1887). Madrid: Biblioteca Nueva.

PANIKKar, Raimon. (1996). El silencio de Buddha. Una introducción al ateísmo religioso. Madrid: Siruela.

PANikKar, Raimon. (1997). La experiencia filosófica de la India. Madrid: Trotta.

PANikKar, Raimon. (2002). "La interpelación intercultural”. En Graciano González Rodríguez Arnáiz (coord.), El discurso intercultural. Prolegómenos a una filosofía intercultural. Madrid: Biblioteca Nueva.

PAnikkar, Raimon. (2005). Espiritualidad hindú. Sanātana dharma. Barcelona: Kairós.

Ramón, L. (2006). "Sabiduría y profecía: dos arquetipos místicos y éticos para nuestro tiempo”. En Francisco Javier Sánchez Rodríguez (ed.), Mistica y sociedad en diálogo. Madrid: Trotta. 107-141.

Vernant, Jean Pierre. (1990). Sobre el individuo. Barcelona: Paidós. 